\title{
MODERNIDADE E MEDIEVALISMO EM GRÓCIO: O DISCURSO DO MÉTODO
}

\author{
Paulo Emúlio Vauthier Borges de Macedo ${ }^{1}$
}

\begin{abstract}
Resumo:
Uma nota distintiva dos autores modernos é a preocupação com o método. Para poder romper com o passado e, ao mesmo tempo, construir um sistema de pensamento seguro, os modernos se voltaram para as ciências "duras" e introduziram o seu método no estudo da Política e do Direito. A autoridade dos textos antigos, por si só, nada teria a ensinar. Muito se debateu sobre a pertença de Hugo Grócio entre os modernos, mas se, por um lado, a presença de um método matemático no seu pensamento for uma das características que definem a qualidade de moderno, então este autor integra as fileiras da Modernidade. Por outro lado, o emprego do método matemático em Grócio revela-se tão repleto de nuanças que induz o leitor a questionar a seriedade dessa escolha. No que concerne o método, o jurista holandês apresenta-se "mais ou menos" moderno, ou "mais ou menos" medieval, a depender da ótica. Ou quiçá a revolução moderna não tenha sido tão revolucionária assim, e Hugo Grócio seria um pensador de transição.
\end{abstract}

Palavras-chave: Hugo Grócio, Modernidade, método.

\section{INTRODUÇÃO}

Poucos estudiosos receberam tantos elogios como Hugo Grócio. Numa das traduções mais consagradas do De Jure Belli ac Pacis para o francês, o tradutor Jean Barbeyrac redige um prefácio repleto de lisonjas. ${ }^{2}$ Também ao prefaciar o livro de um outro autor, Pufendorf - um dos maiores intérpretes de Grócio -, este jurista francês professa a sua admiração pelo filósofo de Delft ao afirmar que o "ilustre Grotius (...) [foi o primeiro que dissipou] aquelas espessas Nuvens de Trevas na qual o Mundo estava, por tanto tempo, envolto" na Idade Média e reacendeu a luz da razão. ${ }^{3}$ Vico o proclamou "o jurisconsulto do gênero humano". John Locke o incluía entre os principais escritores para ser lido por homens civilizados. ${ }^{4}$ Entre, nós, Miguel Reale não esconde a sua admiração: "antes dele não se poderia falar em filosofia do direito em sentido próprio, pois é com o seu livro De Jure Belli ac

\footnotetext{
${ }^{1}$ Doutor em Direito. Professor Adjunto de Direito Internacional da Universidade Federal do Rio de Janeiro (UFRJ) e Universidade do Estado do Rio de Janeiro (UERJ). Vice coordenador do programa de mestrado e doutorado em Direito na Universidade do Estado do Rio de Janeiro (UERJ). Membro da Sociedade Brasileira de Direito Internacional (SBDI) e da Comissão da Área de Direito da CAPES. E-mail: borgesmacedo@hotmail.com.

${ }^{2}$ GROTIUS, Hugues, Le droit de la guerre et de la paix de Hugues Grotius, Trad. J. Barbeyrac, Amsterdam, Pierre de Coup, 1724. pp. I-XLIII.

${ }^{3}$ BARBEYRAC, Jean, "An Historical and Critical Account of the Science of Morality" en PUFENDORF, Samuel. Of the Law of Nature and Nations, Trad. B. Kenneth, London, 1729.p. 79.

${ }^{4}$ Confira os elogios de Locke e Vico em Tuck, Richard, Natural Rights Theories: their origin and development, New York, Cambridge University Press, 1979, p. 63.
} 
Pacis que se apresenta o primeiro tratado de direito natural, ou para melhor dizer, o primeiro tratado autônomo de filosofia do direito." ${ }^{\text {A }}$ Até trezentos anos após a sua morte, os comentários que eram reservados ao autor eram apaixonados e hiperbólicos. Não havia tons de cinza: Grócio era sinônimo de Direito, e os seus livros perfilavam o mesmo status dos clássicos antigos como a República de Cícero.

Todavia, elogios tão rasgados podem encobrir mais do que revelar. Somente uma leitura a partir do contexto cultural em que o próprio Grócio se encontrava pode compreendê-lo melhor. O pensador holandês surge em tempos de transição. De um lado, as forças do novo, que já concebiam a política em termos de unidades nacionais, representadas pela pessoa do Cardeal Richelieu; de outro, as forças do velho, escritores papalistas e imperiais que pregavam a restauração das decadentes instituições centrais da cristandade latina. Neste contexto, o êxito dos escritos de Grócio foi imediato. O De Jure Belli ac Pacis sofreu cerca de 48 impressões apenas em latim e mais de 26 traduções para outros idiomas. Gustavus Adolphus, quando cavalgou pela Germânia durante a Guerra dos Trinta Anos, teria carregado uma cópia deste livro. E sabe-se que, mais tarde, os ingleses usaram os argumentos sobre a livre navegação contra os monopólios holandeses.

O sucesso do jurista holandês foi tão retumbante que engendrou o mito. Em 1661, na Universidade de Heidelberg, Samuel Pufendorf criava a cadeira "direito da natureza e das gentes" para lecionar o direito público moderno e seus institutos: o contrato social, os direitos naturais inerentes ao homem e o direito das gentes. Como livro texto, utilizava o tratado do Direito da Guerra e da Paz. Durante o século seguinte, entre os membros da Escola do Direito da Natureza e das Gentes, formou-se a lenda de um fundador único da disciplina. Importa ressaltar que, em oposição aos elogios tecidos a Grócio, a todos os autores anteriores se reservavam expressões como "obscurantismo" e "passado medieval".

Nos primeiros trezentos anos que se passaram desde o seu nascimento, Hugo Grócio foi considerado sozinho o pai de todo um ramo do Direito, o direito internacional público, bem como o pai da filosofia do direito moderna e da noção de direito subjetivo. A sua influência fazia-se sentir em outras paragens também, como o direito internacional privado. Sua obra era revolucionária e pioneira em todos os campos que adentrasse. Grócio era o maior jurista de todos os tempos e o primeiro pensador da Política e do Direito da modernidade.

Contudo, a década de 1860 marca um momento de inflexão neste entusiasmo por Grócio em razão de um fato bastante inusitado: a descoberta do De Jure Praedae Commentarius, obra que autor jamais publicou e que havia desaparecido. Em vez de chamar as atenções para o jurista de Delft, as diversas referências aos escolásticos, em especial ao teólogo de Salamanca, serviram de argumentos à disputa da paternidade do direito

\footnotetext{
${ }^{5}$ REALE, Miguel, Horizontes do Direito e da História, 3 ed., São Paulo, Saraiva, 2000, p. 103.

${ }^{6}$ HAGGENMACHER, Peter, "La place de Francisco de Vitoria parmi les fondateurs du droit international" en Truyol y Serra, Antonio et al., Actualité de la Pensée Juridique de Francisco de Vitoria, Bruxelles, Bruylant, Centre Charles De Visscher pour le droit international, 1988, pp. 27-28.
} 
das gentes. O próprio prefácio da edição de Gerhard Hamaker salienta a influência decisiva dos espanhóis. No final do século, a literatura revisionista multiplica-se dentro e fora da Espanha. Neste país, Eduardo de Hinojosa enfatiza, de modo específico, a importância dos teólogos espanhóis. E, na Bélgica, Ernst Nys e o suíço Alphonse Rivier retiram a originalidade de Hugo Grócio:

[Quando se afirma que Grócio é o pai do direito natural e o pai do direito das gentes], quer afirmar-se que uma disciplina toda nova saiu de sua cabeça, que ele inventou ou imaginou, por um tipo de intuição divina, as até então desconhecidas regras da guerra, da paz e das relações entre os Estados, entre soberanos, as alianças, as embaixadas? Nada seria mais contrário quer à lógica das coisas, quer à verdade. Uma quantidade de canonistas, de legistas, de publicistas escreveram, desde a Idade Média, sobre esses temas diversos, bem como sobre assuntos pertencentes ao direito natural. ${ }^{7}$

Então, em 1874, sir Thomas Erksine Holland, na sua famosa aula inaugural em Oxford, retira, em definitivo, Grócio de seu pedestal e apresenta Alberico Gentili como o verdadeiro criador do direito internacional. O jurista de Delft teria sido apenas o seu discípulo mais importante e, certamente, o mais conhecido. ${ }^{8}$ Desde então, o prestígio do jurista holandês só caiu. James Brown Scott, ao discutir a paternidade do direito internacional, embora ainda dispense muita deferência ao jurista de Delft, introduz uma crítica sutil ao considerar Vitória o expositor inicial, Suárez o filósofo, mas relega a Grócio o epíteto de sistematizador. No mesmo parágrafo, considera o holandês, por fim, um discípulo da escola hispânica. ${ }^{9} \mathrm{Na}$ filosofia política, Paulo Merêa assevera que Não há, pois, divergência essencial entre a doutrina de Suárez e a de Grócio; pelo contrário, parece fora de dúvida que aquela inspirou o filósofo holandês a ponto de este a reproduzir nos seus traços principais. (...) O confronto não resulta, aliás, favorável ao filósofo holandês (...) é manifesta a inferioridade deste último. (...) A influência de Grócio foi, fora dos meios católicos, muito mais importante e decisiva do que a de Suárez, mas isso se deve, não já ao mérito intrínseco da construção, mas, numa enorme medida, à circunstância de o autor ter imprimido ao pensamento uma feição eminentemente simpática às tendências racionalistas da sua época. ${ }^{10}$

\footnotetext{
7 “Est-ce à dire qu'une discipline toute neuve lui ait jailli du cerveau, qu'il ait inventé ou imaginé, par une sorte d'intuition divine, les règles inconnues jusqu’à lui de la guerre, de la paix, des raports entre États, entre souverains, des alliances, des ambassades? Rien ne serait plus contraire, soit à la logique des choses, soit à la verité. Quantité des canonistes, des légistes, des publicistes ont écrit dès le moyen âge sur ces divers sujets, comme aussi sur les sujets appartenant au droit naturel." (Rivier, Alphonse, Note sur la littérature du droit de gens avant la publication du Jus Belli ac Pacis de Grotius (1625), Bruxelles, Académie Royale de Belgique, 1883). Confira também Hinojosa, Eduardo, Influencia que tuvieron en el Derecho Público de su pátria y singularmente en el Derecho penal los filósofos y teólogos españoles, anteriores a nuestro siglo, Madrid, Reus, 1890 e Nys, Ernest, Le Droit de la Guerre et les précurseurs de Grotius, Bruxelles et Leipzig, Murquardt, 1882.

${ }^{8}$ HOLLAND, Thomas E., "Alberico Gentili: an inaugural lecture delivered at All Souls College", November 7, 1874, Studies in International Law, Oxford, Clarendom Press, 1898, pp. 1-23.

${ }_{9}^{9}$ SCOTT, J. B., The Catholic Conception of International Law, Washington D.C., Georgetown University Press, 1934, p. 184.

${ }^{10}$ MERÊA, Paulo, "Suárez, jurista, O problema da origem do poder civil", Estudos de Filosofia Jurídica e de História das Doutrinas Política, Lisboa, Imprensa Nacional-Casa da Moeda, 2004, pp. 178-179 e 181.
} 
De pioneiro, Grócio se tornou um simples continuador. Como é demonstrado pelo título mesmo da obra já referida de James Brown Scott, Grócio perde a paternidade do direito internacional e passa a figurar como um dos membros da Escolástica Espanhola. O fato dele não ser católico nem espanhol não importou muito. E as críticas proliferaram. O professor Vollenhoven atesta que não há uma língua ocidental em que não houvessem surgido trabalhos que mostraram os erros de Grócio nos seus objetivos e no seu método, e que indicaram como ele deveria ter escrito para produzir um livro mais satisfatório de direito internacional. ${ }^{11}$ Parece que o teólogo holandês sofre de uma sina que é a de ser lido não em função de seus problemas e propósitos, mas dos preconceitos dos próprios leitores. Todas essas comparações padeciam, no entanto, de graves imprecisões e de certa intencionalidade para denegrir o autor.

Essas duas interpretações - a entusiástica e a revisionista - ressentem-se de uma leitura um tanto anacrônica: ambas procuram identificar no pensamento grotiano os elementos do direito internacional contemporâneo. Apenas recentemente, com a publicação, em 1983, da tese de doutorado de Peter Haggenmacher, Grotius et la doctrine de la guerre juste, as obras de Grócio são analisadas à luz das preocupações de sua própria época. Em termos gerais, segundo Haggenmacher, Grócio não escreveu um livro de direito internacional, mas de direito de guerra medieval, a doutrina da guerra justa. $\mathrm{O}$ escritor holandês encontrava-se inserido nos debates escolásticos sobre a licitude da guerra. $\mathrm{O}$ direito da guerra, assim, não consiste num dos tópicos de direito das gentes. Ao contrário, é o jus gentium que corresponde a uma das fontes do direito da guerra, ao lado do direito natural e do direito divino voluntário.

Não se deve rotular um autor como Grócio de moderno ou medieval. Após séculos de distanciamentos, já se possui noções preconcebidas sobre a quintessência do medievalismo e da modernidade. Mas esses termos não operam numa lógica binária, em que a presença de um exclui a do outro. No jurista holandês, há um pouco dos dois.

Também em relação ao método de Hugo Grócio houve exageros. Van Eikema Hommes chega a atribuir a Grócio a leitura de Descartes enquanto trabalhava no De Jure Belli ac Pacis. ${ }^{12}$ Cabe ressaltar o anacronismo dessa afirmação pois o Discurso do Método só veio à lume em 1637, e as Meditações em 1641! As linhas que Grócio dispensou ao seu método, como será visto a seguir, de fato, possuem um tom bastante moderno. Mas é necessário analisá-las à luz dos debates da época, não da imagem caricata que o leitor de hoje tem sobre modernidade e medievalismo.

\footnotetext{
${ }^{11}$ VOLLENHOVEN, Cornelius van, Grotius and the Study of Law. AJIL, v. 19, n. 1, janeiro de 1925, p. 1.

${ }^{12}$ EIKEMA HOMMES, Hendrik van, Grotius on Natural and International Law, Netherlands International Law Review, v. XXX, 1983 p. 64.
} 


\section{PANORAMA INTELECTUAL SOBRE O PROBLEMA DO MÉTODO NO INÍCIO DO SÉCULO XVII}

Uma característica típica da modernidade consiste na ênfase quanto ao método. Filósofos como Hobbes acreditavam que as únicas ciências a progredirem o bastante "para transformar radicalmente a concepção do cosmos haviam sido as que aplicaram o procedimento rigorosamente demonstrativo da geometria" ${ }^{13}$. $\mathrm{O}$ atraso verificado no estudo do homem e da sociedade deve-se, em boa medida, a um defeito de método. Para essa depuração, o alvo principal da crítica dos modernos é Aristóteles por duas razões. A primeira diz respeito à autoridade que os textos do Estagirita adquiriram no medievo, os quais eram lidos acriticamente e dispensavam a apresentação de provas. Grócio comunga desta concepção. Além disso, Aristóteles partiria de um realismo epistemológico que foi considerado um tanto ingênuo, uma vez que não questiona a existência de entes externos à subjetividade. Céticos como Pierre Charron asseveraram que não se poderia construir um conhecimento seguro na Física, porque a percepção humana pode ser ilusória e, na Ética, por causa da pluralidade de costumes, crenças e comportamentos nos mais diversos locais. No final do século XVI, o ataque que os céticos haviam promovido ao aristotelismo parecia definitivo, mas eles apenas haviam desconstruído um pensamento e não apontaram nenhuma solução alternativa. Coube aos modernos buscar uma saída. ${ }^{14}$

A preocupação que os escolásticos - mesmo os escritores da Escolástica Espanhola - dispensam ao método não possui fundamento epistemológico. O chamado "método escolástico" constituía tão-somente uma forma de exposição mais didática de conteúdos bastante complexos. Trata-se de um método bastante didático de exposição que principia pela apresentação de uma proposição teológica ou filosófica, seguida de uma objeção ou dúvida à proposição inicial. Conclui-se o argumento com a solução do problema e com a resposta à objeção. ${ }^{15}$ Não o empregavam em todas as obras, apenas naquelas que se destinavam aos alunos. O próprio autor da Summa, nos seus demais trabalhos, distanciou-se dessa fórmula.

Ocorre que, em comparação com os trabalhos dos juristas pré-modernos, os escolásticos pareciam produzir uma ciência mais intrincada, mas também mais apurada - o que se deve à assunção da lógica aristotélica no lugar da retórica. No rigor apresentado pelos escolásticos não há nada de moderno, nenhuma relação com a

\footnotetext{
${ }_{13}$ BOBBIO, Norberto, Thomas Hobbes, Trad. Carlos Nelson Coutinho, Rio de Janeiro, Campus, 1991, p. 28. Aos 40 anos, Hobbes, acidentalmente, trava contato com a obra Elementos de Geometria de Euclides. Ele abre o livro na quadragésima sétima proposição e considera um absurdo. Mas a demonstração remete à proposição anterior, que remeteu à que vinha antes e, assim, sucessivamente até um primeiro axioma evidente per se e incontestável. Graças a isso, apaixonou-se pela geometria. (Aubrey, John, Brief Lives, Edited by Richard Barber, Woodbridge, Suffolk, The Boydell Press, 1982, p. 152).

${ }^{14}$ TUCK, Richard, Grotius, Carneades e Hobbes, Grotiana, v. 4, 1983, p. 45.

${ }^{15}$ CEDRONI, Lorella, La Comunitá Perfetta: il pensero politico di Francisco Suárez, Roma, Studium, 1996, p. 39.
} vol.07, n. 02, Rio de Janeiro, 2014.pp. 1010-1033 
ciência moderna; trata-se, tão-somente de Aristóteles. Aquela ciência mais elevada dos princípios e das causas ${ }^{16}$ - a Teologia, que, à época, também se dedicava ao estudo da justiça e das leis -, como se encontra bastante afastada do mundo sensível, só pode tornar-se inteligível mediante a Lógica, a disciplina que estuda as operações formais do pensamento. É dessa forma que se deve entender o que os escolásticos se propunham ao estudar o seu objeto.

As ciências práticas, como a Ética e o Direito, que visam o bem viver, não eram expressas de acordo com os cânones da Lógica formal, mas conforme outra lógica que procurava o convencimento e a persuasão: a Retórica. Ela, em conjunto com a Tópica, é que constituía a arte cívica do humanismo, a arte do cidadão, dotado de uma boa oratória, que influi na política da sua cidade. Os grandes juristas medievais italianos, como Bártolo, Baldo ou Paulo Castrense, dos quais Grócio descende, ao menos, de maneira indireta ${ }^{17}$, empregavam um método baseado na persuasão e na casuística. Contudo, ainda que não houvesse deixado de se valer da Retórica, Grócio parece ocupar-se do método como um moderno.

O debate sobre o método não importava só para a Filosofia; também o Direito passou a sentir essa necessidade. O mos italicus, o modo medieval de fazer ciência do Direito já mostrava sinais de exaustão. Ele se caracterizava pela redação de longos manuais sobre tudo que poderia existir do Direito, pelo uso da retórica e do condicionamento imposto pelas instituições romanas. Mas, aos poucos, começam a surgir obras sobre temas específicos, como o direito das embaixadas, e, em consequência, deveria pensar-se uma nova sistematização do Direito, diferente daquela do codex justiniano. O problema resumia-se a encontrar um critério definidor. Uma classificação ratione materiae não parecia óbvia, e a sistematização com base nas actio romanas ainda era tentadora. $^{18}$

A tradição medieval continua a dominar o direito civil na região da Itália e em diversos Estados alemães, além de persistir também em todo o direito canônico; porém, em França, o humanismo vai criar uma tendência nova: o mos gallicus, o modo francês de fazer ciência do Direito. Seus principais expositores são juristas como Ulrich Zasius, Guillaume Budé e Andreas Alciatus. No direito da guerra, destacam-se Connan, Le Douaren e Doneau. Esta corrente concentrou-se na Universidade de Bourges, mas obteve boa acolhida nos Países Baixos, sobretudo em Louvain, depois em Leyden. Cabe observar que Grócio estudou nesta universidade, e é significativo que tenha se doutorado em Orléans. O mos gallicus vai apresentar duas grandes vertentes: uma dominada pela

\footnotetext{
${ }^{16}$ Em Aristóteles, era a Metafísica, mas, para os escolásticos, era a própria Teologia. Esta se identificava com a Metafísica somente quando aborda o ens commune; “filosofia primera', en cuanto considera las causas primeras de las cosas; 'teologia', en cuanto considera las sustancias que no tienen materia, Dios, etc” (Sciacca, Michele, Perspectiva de la metafisica en Sto. Tomas, Madrid, Speiro, 1976, p. 50).

${ }^{17}$ HAGGENMACHER, Peter, "Grotius and Gentili: a reassessment of Thomas E. Holland's inaugural lecture" en Bull, Hedley; Kingsbury, Benedict; Roberts, Adam (ed.), Hugo Grotius and International Relations, Oxford, New York, Oxford University, Clarendon Press, 2002, p. 161.

${ }^{18}$ WIJFFELS, Alain, Early-Modern Literature on International Law and the Usus Modernus, Grotiana, v. 16-17, 1995-1996, pp. 3839.
} 
História e a Filologia, e a outra por uma reflexão dogmática, sistemática e metodológica. Estas duas tendências, por vezes, combinam-se, como no caso de Grócio, em que o esforço de sistematização não exclui a intrusão daquelas duas disciplinas no domínio jurídico. Não há, contudo, uma oposição frontal ao mos itallicus; trata-se mais de um alargamento e transformação e menos de uma ruptura e rejeição. ${ }^{19}$

Ao comparar a opus magna de Alberico Gentili, autor típico do humanismo jurídico pré-moderno, com a de Hugo Grócio, Peter Haggenmacher aponta a grande proximidade entre ambas: o mesmo tema, a estrutura e os tópicos similares, entre outras semelhanças. Ainda assim, há uma diferença fundamental. Em Gentili, "o que, por vezes, pode assemelhar-se a um sistema não passa de uma habilidosa e elegante discussão das questões tópicas como originadas e desenvolvidas por sucessivas gerações de juristas e teólogos no campo específico do direito da guerra." ${ }^{20} \mathrm{O}$ seu método compõe-se de casuísmos e arrolamento de topoi, e está bem inserido na tradição medieval da disputatio. O jurista de Oxford estudou em Perugia e era um descendente espiritual dos bartolistas, da escola medieval de jurisprudência. Ele se identificou de forma consciente com essa tradição. Grócio, por sua vez, embora conhecesse a fundo os mestres italianos, mostra-se uma genuína criatura do mos gallicus. "O que os sistematizadores franceses fizeram para o direito civil romano - uma construção ordenada de matérias arroladas no Corpus Juris Civilis - ele iria conseguir para todo o campo encontrado além do direito civil, isto é, o jus belli ac pacis (...)."21 O problema todo resume-se a um problema de compreensão do mos gallicus: uma simples continuação do mos itallicus, corrente inserida portanto dentro do humanismo jurídico, um período de gestação da modernidade, mas que não se confunde com ela, ou um momento inicial da própria modernidade.

\section{O MÉtodo EM HUGO GRÓCIO: A PROPOSTA NO DE JURE PRAEDAE COMMENTARIUS}

O texto em que Grócio mais se debruça sobre o próprio método é o De Jure Praedae. Em 25 de fevereiro de 1603, o marechal Jacob van Heemskerck, a serviço da VOC (sigla em holandês para Vereenigde Oostindische Compagnie, Companhia das Índias Ocidentais Unidas, que havia sido recém criada), captura, no estreito de Málaca, a carraca portuguesa Santa Catarina e o seu conteúdo - cumpre salientar que era o período de união das coroas portuguesa e espanhola. O que a companhia havia feito era nada mais nada menos do que um ato de guerra. Isso gerou uma polêmica internacional bastante calorosa sobre se a VOC teria ou não o direito de apresar.

\footnotetext{
${ }^{19}$ HAGGENMACHER, Peter, Grotius et la doctrine de la guerre juste, Genève, Paris, Heige, Presses Universitaires de France, 1983, pp. 47-48.

20 "What may at times look like a system is hardly more than a skilful, often quite elegant, discussion of the topical questions as raised ad formulated by successive generations of lawyers and theologians in the particular filed of the law of war." Haggenmacher, Peter, Grotius and Gentili. op. cit, nota 13, pp. 160-161.

${ }^{21}$ IBIDEM, p. 161. "What the French systematizers had done for Roman civil law - an orderly reconstruction of the materials afforded by the Corpus Juris Civilis according to logical principles - he was to accomplish for the whole field lying beyond the ken of civil law, that is, the jus belli ac pacis (...)".
} 
Mesmo dentro dos Países Baixos, o episódio causou descontentamento e mal-estar. Alguns acionistas da companhia eram menonitas pacifistas, cristãos piedosos e herdeiros da tradição irenista de Erasmo. Eles passaram a vender suas ações e a doar o capital para a caridade, com o propósito deliberado de censurar a VOC, pois acreditavam que a carga não poderia ser apresada e que qualquer guerra representaria um mal. Grócio foi encarregado de promover a justificação. ${ }^{22}$

Em 1605, é composto um manuscrito intitulado De Jure Praedae Commentarius, do qual, em 1609, é extraído e publicado o capítulo doze com algumas pequenas emendas, um texto conhecido como Mare Liberum. Cumpre salientar que a obra toda, composta de 163 folhas, teve a existência ignorada durante dois séculos e meio, quando foi descoberta, de forma fortuita, em 1864. No De Jure Praedae, já se prefiguram os primeiros delineamentos sobre o problema da guerra justa. Grosso modo, Grócio argumenta que a VOC teria direito ao butim, pois os Países Baixos se encontravam engajados numa guerra legítima contra a Espanha, mesmo diante do fato de a companhia não constituir uma autoridade pública. O segundo argumento aparece no Mare Liberum: o da livre navegação dos mares. Aqui, Grócio precisava contornar uma Bula Papal de Alexandre VI, de 14 de maio de 1493, a Bula Inter Coetera (posteriormente modificada pelo Tratado de Tordesilhas de 7 de junho de 1494), que concedia aos portugueses a soberania sobre a rota de navegação. Não seria tarefa fácil, mas Grócio era habilidoso o suficiente para invocar, como autoridades na defesa de sua causa, Santo Tomás de Aquino e Francisco de Vitória, dois ícones do pensamento católico.

A organização do De Jure Praedae apresenta-se admiravelmente clara; sobretudo, em função de uma divisão em três partes: uma discussão do problema sob o ângulo do Justo (que abrange os capítulos II a XIII), depois sobre o Honesto e, por fim, sobre o Útil (os quais correspondem, quase como um apêndice, aos capítulos XIV e XV). A análise do Justo domina todo o conjunto e se subdivide em três partes: a Dogmatica (II a X), na qual se esboçam os princípios gerais, a Historica (XI), em que se relatam os fatos da espécie, e o Examen (XII e XIII), que representa a aplicação prática dos princípios aos fatos, a argumentação jurídica propriamente dita para justificar o apresamento da carga da nau Catarina. Trata-se de uma construção bastante ordenada. No segundo capítulo, quando Grócio inicia a Dogmatica, ele expõe todas as premissas na forma de nove definições (regulae), que representam diversos tipos de jus organizados de acordo com a hierarquia dos seus respectivos legisladores. A partir dessas regulae, decorrem treze preceitos (leges), dos quais Grócio deriva diversas proposições (conclusiones corollaria) nos capítulos subsequentes.

O título do primeiro capítulo enuncia o propósito de toda a monografia: Exordium, Argumentum, Distributio, Methodus, Ordo Operis. No Exordium, para o seu público menonita, ele indica que a natureza do

\footnotetext{
${ }^{22}$ HAGGENMACHER, Peter, op. cit., nota 15, p. 53. Os acionistas cogitaram até mesmo de fundar, em solo francês, sob os auspícios do rei Henrique IV, uma sociedade concorrente mais conforme ao "espírito dos evangelhos".
} 
debate acerca do incidente decorre essencialmente da ideia de justiça. O estudo do Direito, à época, ainda não é dissociado da antiga virtude do justo. Explica ainda o enquadramento de sua proposta nos ramos do Direito: o direito de presa, o qual se insere no direito da guerra. Seu problema é, mesmo na obra de juventude, o jus belli. ${ }^{23}$ No Argumentum, narra o incidente relativo ao Catarina e antecipa a conclusão geral: a legitimidade do ato do almirante holandês. Na Distributio, justifica o plano geral de composição (o Justo, o Honesto e o Útil) e traça um interessante paralelo retórico. $\mathrm{O}$ autor evoca, a todo o momento, a "ajuda dos três principais gêneros oratórios mencionados por Cícero e Quintiliano - iudicium, laudatio e deliberatio - as quais presidem respectivamente as três discussões do Iustum, do Honestum e do Utile"24. Trata-se do que se poderia chamar de uma "coincidência eclética".

Deve ressaltar-se o fato de que Grócio distingue Methodus de Ordo: esta seria a disposição geral dos elementos da demonstração, e aquele designa o procedimento de demonstração propriamente dito. Esta distinção advém das influências de lógicos italianos, em especial da escola paduana. Jacobus Zabarella, colega mais velho de Galileu na Universidade de Pádua, sob a influência de Aristóteles, Euclides e Averróis, inicia, neste local, as investigações que dariam origem ao método dos modernos. Ele o preconizou como um regressus: a fim de se obter uma ciência certa de um fenômeno conhecido de maneira imperfeita, deve remontar-se às suas causas e, somente após uma reflexão sobre estas causas e seus possíveis efeitos in abstractu, pode retornar-se, em seguida, ao fenômeno inicial. ${ }^{25}$

Paira certa indefinição, contudo, em relação ao nome e às espécies de métodos criados por essa escola. Pode-se denominá-lo de método geométrico, porque os Elementos de Euclides representam o paradigma da demonstração científica. E pode-se chamá-lo de método matemático, uma vez que a geometria é uma parte da matemática. Contudo, há uma sutil diferença entre ambos. O método geométrico procede de Euclides, e o método matemático (empregado por Galileu e Newton) identifica-se com a física moderna. Um se preocupa com a explicação dos axiomas, a clareza dos conceitos e o rigor demonstrativo, e o outro se ocupa da observação e

\footnotetext{
${ }^{23}$ GROTII, Hugonis, De Jure Praedae Commentarius, La Haye, Hamaker, Nijhoff, 1868, pp. 1-4.

${ }^{24}$ HAGGENMACHER, Peter, op. cit., nota 15, p. 57 : “(...) l'aide des troix principaux genres oratoires mentionnés par Cicerón et Quintilien - iudicium, laudatio et deliberatio - et qui président respectivement aux troix discussions du Iustum, du Honestum et de l'Utile."

${ }^{25}$ IBIDEM, p. 68. Grócio enviou uma carta a Galileu na qual se confessa um admirador. (Grotii, Hugonis, Epistolae Quotquot reperiri potuerunt; In quibus praeter hactenus Editas, plurimae Theologici, Iuridici, Philologici, Historici \& Politici argumenti occurrunt. Amstelodami, P. \& I. Blaev, 1687, Carta a D. Galilaeo Galilaei, n. 654, p. 266). No entanto, os trabalhos de Galileu, Saggiatore (1623), Diálogo sobre os dois grandes sistemas do mundo (1632) e Discursos e demonstrações matemáticas concernentes às duas ciências novas (1638) são bastante posteriores ao De Jure Praedae. Portanto, revela-se provável que Grócio, embora interessado, houvesse acompanhado a revolução no método apenas em parte.
} 
da experimentação, com a mensuração dos dados em linguagem matemática. ${ }^{26}$ Como se verá, no De Jure Praedae, Grócio compara o seu proceder com o dos matemáticos, o que parece evocar este último método.

Para Alfred Dufour, na história da modernidade, essa sutil distinção acaba por criar dois métodos importantes. O geométrico foi empregado por Descartes e se tornou conhecido como "resolutivo-compositivo". Implica a decomposição (ou resolução) de um fenômeno aos seus elementos mais simples, para o emprego de relações que o expliquem (velocidade, espaço, tempo) e, depois, a sua reconstituição (ou composição) para a formulação de um princípio ou lei geral em que o fenômeno se enquadre. Este método foi empregado por Hobbes. O método matemático, por sua vez, originou-se do seio da escola paduana e centra-se mais na demonstração do que na invenção. Zabarella começou a desenvolvê-lo, mas é Galileu que o expõe quando descobre a lei da queda dos corpos. A maneira de demonstrar é dupla: por análise e por síntese. A análise mostra como a coisa foi montada e como os efeitos dependem da causa. A síntese examina as causas pelos efeitos, pondera a verdade nas conclusões e propõe definições, axiomas e teoremas. Assim, podem perceber-se como as consequências estão nos antecedentes. ${ }^{27}$

Embora parecidos, eles não se confundem porque o matemático pressupõe a existência de um esquema conceitual no qual se possa aplicar uma hipótese, como, v.g., o vácuo absoluto na queda livre, e o outro um axioma do qual se possam extrair teoremas. Mas, de fato, há muitas semelhanças entre ambos. Os dois métodos são, em sua inteireza, racionais: não há nenhum dado da empiria. A única experimentação que pode existir resume-se a comprovações matemáticas e conceituais. Isso significa que a desconfiança cética em relação aos sentidos foi incorporada.

Outrossim, a modernidade conheceu, ainda, outros métodos. Como os dois já descritos representam ancestrais diretos do método hipotético-dedutivo da Física moderna - e esta corresponde ao modelo de ciência -, por vezes, negligenciam-se outras formulações metodológicas, algumas não tão avessas aos sentidos. Cabe recordar, não obstante, o trabalho dos empiristas ingleses Bacon, Locke e Hume. Em verdade, o jovem Grócio jamais poderia ter lido a obra destes, mesmo a do primeiro, mas eles servem para salientar que não existe apenas a modernidade galileo-cartesiana. No final do século XVI e no século seguinte, o método se tornou uma preocupação generalizada.

De volta ao De Jure Praedae, no Methodus, Grócio afirma que deverá recorrer a dois tipos de procedimentos para provar suas afirmações, a ractio naturalis e a auctoritates. Neste instante, o autor reage não contra Aristóteles, mas contra o método tradicional dos juristas que transpõem, sem o menor cuidado, as regras e os princípios do direito civil e canônico a uma esfera (o direito da guerra) em que eles perdem sua validade. Este

\footnotetext{
${ }^{26}$ DUFOUR, Alfred, L'influence de la méthodologie des sciences physiques et mathématiques sur les Fondateurs de l'École du Droit naturel moderne (Grotius, Hobbes, Pufendorf), Grotiana, v. I, 1980, p. 37.

${ }^{27}$ IBIDEM, pp. 38-39.
} 
domínio, em Grócio, caracteriza-se não somente pela sua “internacionalidade”, mas pela inexistência de uma autoridade judiciária. Assim, sem a possibilidade de recurso a ela, as instituições de sistemas jurídicos hierarquizados, como são o canônico e o civil - e entre estas instituições, de um modo geral, inserem-se as actio romanas -, não podem ser aplicadas.

Não se pode, portanto, proceder como os juristas normalmente faziam e aplicar institutos do direito civil ou do direito canônico ao direito da guerra. Grócio encontra uma solução bastante interessante para este problema: “(...) 'nada escrito é válido entre inimigos; porém, os costumes são observados por todos, mesmo quando se atingiu o ódio extremo'. Na passagem citada, o termo 'costumes' é equivalente ao conceito de Cícero na frase 'lei não escrita, mas lei que brota da Natureza' (...)"28. Entre inimigos, pessoas que nutrem uma desconfiança recíproca, deve apelar-se para um direito não-escrito, indicado pela concordância dos mores dos mais diversos povos, o que representa nada menos do que a manifestação da razão natural. Somente este jus possui validade mesmo entre inimigos. E, uma vez que a lei natural, ao lado do direito divino e do direito das gentes, constitui uma das fontes do direito da guerra, faz-se necessário conceber uma forma de descobri-la. Visto que o direito natural é racional, pode ser revelado a priori, pelos mecanismos intelectivos da própria razão que todos os homens desfrutam. O método a posteriori, os testemunhos das Escrituras ou de autoridades humanas, serve apenas para confirmar o que a razão já desvelou: quando todos concordam sobre determinado efeito, é provável que ele provenha de uma causa comum. No final do tópico, o espaço e o tempo gastos com a explicação da importância da autoridade - menos de uma frase inteira - já revelam que o papel desempenhado por este método se mostra bem menor do que o da ractio naturalis.

A razão humana e o recurso à autoridade constituem, pois, os métodos que Grócio emprega. Nenhum deles guarda qualquer semelhança com aqueles já descritos responsáveis pela revolução moderna. Ainda assim, a estrutura axiomática-dedutiva da obra parece encerrar alguma inspiração do método matemático. Mas não é no Methodus que Grócio explica esta influência, e sim na Ordo.

Quanto ao resto, é necessário aos nossos propósitos ordenar a discussão da seguinte maneira: primeiro, iremos estabelecer o que é universal como uma proposição geral; depois, iremos gradativamente esmiuçar essa generalização, adaptando-a para a natureza específica do caso em exame. Assim como os matemáticos mormente fixam antes de qualquer demonstração uma afirmação preliminar de determinados axiomas sobre os quais todas as pessoas concordam, a fim de haver um ponto fixo do qual se pode traçar a prova do que se segue, então também iremos apontar determinadas regras e leis de natureza geral, apresentá-las como assunções preliminares que

\footnotetext{
${ }^{28}$ GROTII, Hugonis, op. cit., nota 19, p. 6. “( ... ) 'Eorum sane quae scripta sunt nihil inter hostes valet; mores autem servantur ab omnibus, etiam cum ad extremum odii processerint.' Ubi mores idem sunt, quod apud Tullium 'non scripta sed nata lex' (...)”
} 
deverão ser reexaminadas e demonstradas novamente, com o propósito de criar uma fundação sobre a qual outras conclusões podem se apoiar de forma segura. ${ }^{29}$

Parece uma descrição do método que só um moderno poderia conceber. No parágrafo seguinte, Grócio pede desculpas ao leitor por alguma gafe que possa porventura cometer, em razão do ineditismo do seu intento. De fato, se o autor pretendia transpor o método das ciências demonstrativas para a filosofia moral, ele se antecipou em três decênios ao Discurso do Método.

Não obstante, essa tese de que Grócio desenvolve uma reflexão moderna sobre o método precisa superar um grande inconveniente: a alusão ao ofício dos matemáticos insere-se na Ordo, não no Methodus. Trata-se de um dado relevante. Para os modernos, isso constituía um problema de método, não de simples organização. Para Grócio, os métodos utilizados eram dois: a derivação da ractio naturalis e a confirmação pelas auctoritates. É a sua organização que se inspira no proceder dos matemáticos. O jurista holandês buscou tãosomente uma forma original - e, com toda a certeza, mais "ordeira" - de arrumar conteúdos antigos; como um bom advogado, procurou uma maneira mais didática e convincente de expor seus argumentos. A alusão representa apenas uma simples comparação, e não a transposição de um método de outra ciência para o domínio do Direito. Haggenmacher afirma que o fato de "o proceder como os matemáticos" se encontrar na Ordo, não no Methodus, implica que, no autor, apesar das aparências, o método não constitui em si mesmo um objeto de reflexão autônoma. O método, a ordem e as desculpas antecipadas ao leitor encontram-se todos no mesmo patamar de abstração; destinam-se aos prolegômenos, segundo capítulo do livro, e não tratam da questão central, a materia belli. Não há dúvidas de que, em relação às obras anteriores que versam sobre o direito da guerra, o sistema geral do De Jure Praedae apresenta algo novo. E a novidade da exposição é comparável ao trabalho dos matemáticos, mas não se identifica com o ofício deles em si. ${ }^{30}$

Ademais, ainda que minorado, o recurso à autoridade - deplorado pelos modernos - persiste como importante meio de prova em Grócio. E, além disso, nos capítulos seguintes, ele torna a confundir a separação que havia tão bem esboçado entre as duas fontes de comprovação.

Se, de um lado, o emprego de uma estrutura axiomático-dedutiva nos prolegômenos aproxima Grócio dos modernos; de outro, o verdadeiro peso que ele confere a este elemento o afasta deles. A imprecisão na referência aos matemáticos revela que o teólogo holandês, embora atento às discussões sobre o método de seu tempo, não gozava de um contato direto com os debates da escola paduana. Conforme Vermeulen, parece

\footnotetext{
${ }^{29}$ IBIDEM, p. 6. "Ordo autem instituto hic convenit, ut initio quid universim atque in genere verum sit videamus, idque ipsum contrahamus paulatim ad propositam facti speciem. Sed quemadmodum mathematici, priusquam ipsas demonstrationes aggrediantur, communes quasdam solent notiones, de quibus inter omnes facile constat praescribere, ut fixum aliquid sit, in quo retro desinat sequentium probatio, ita nos quo fundamentum positum habeamus, cui tuto superstruantur caetera, regulas quasdam et leges maxime generales indicabimus, velut anticipationes, quas non tam discere aliquis, quam reminisci debeat."

${ }^{30}$ HAGGENMACHER, Peter, op. cit., nota 15, p. 69.
} 
provável que a fonte desse método/comparação matemático de Grócio provenha não de Galileu ou Zabarella, mas do físico Simon Stevin, amigo íntimo da família De Groot. ${ }^{31}$

\section{O Método em Hugo Grócio: a proposta no De Jure Belli ac Pacis}

No De Jure Belli ac Pacis, o tratamento dispensado ao método na obra de juventude sobrevive somente como reminiscência; há algumas poucas referências esparsas nos prolegômenos. Grócio principia toda a discussão do seu intento com a afirmativa de que, em relação ao direito das gentes, "poucos escritores tentaram entrar nesse campo, ninguém tentou até o presente fazer disso um tratado completo e metódico" ${ }^{32}$. Essa asserção pode parecer um tanto auto elogiosa e, até mesmo, despropositada, visto que o próprio autor sabia da não-originalidade de seu intento. Contudo, a ênfase deve ocorrer nas palavras "completo" e "metódico". Nos parágrafos 36 e 37 dos prolegômenos, ele retoma essa ideia e faz expressa referência a diversos escritores que o precederam, mas esses "autores pouco disseram sobre assunto tão fértil e a maioria o fez mesclando ou confundindo sem ordem alguma o que é relativo ao direito natural, ao direito divino, ao direito das gentes, ao direito civil, que decorrem de cânones $^{\text {"33 }}$ (grifo nosso). Aquilo que Grócio se considera diferente dos demais se resume ao tratamento: em relação aos dos seus predecessores, o seu tratado mostra-se mais completo e ordenado.

Embora tanto o De Jure Praedae Commentarius como o De Jure Belli ac Pacis abordem a materia belli, a diferença de propósito entre as duas obras salta aos olhos. Nesta última, o jurista holandês almeja a completude. Esta intenção não poderia apresentar-se vinte anos antes porque o De Jure Praedae era o trabalho não de um filósofo, mas de um advogado, de alguém que defendia uma causa. Revela-se bastante sugestivo o fato de que, no epílogo de um livro, o autor implora a Deus para exaltar a sua pátria e frustrar os desígnios cruéis de seus inimigos, e, no parágrafo final do outro, o seu apelo a Deus constitui uma intercessão pela humanidade. ${ }^{34}$

Esse comprometimento científico torna o De Jure Belli ac Pacis um texto de teoria pura. À luz dessa informação, é que se deve compreender a nova referência aos matemáticos:

Seria injurioso para mim pensar [ sic] que não me preocupei de nenhuma das controvérsias de nosso século, seja das que surgiram, como daquelas que se pode prever que possam surgir. De fato, afirmo que, assim como os

\footnotetext{
${ }^{31}$ VERMEULEN, Ben, "Simon Stevin and the Geometrical Method in De jure praedae, Grotiana, v. 4, 1983, p. 64.

32 “(...) attigeunt pauci, universum ac certo ordinem tractavit hactenus nemo (...)” (Grotii, Hugonis, De Iure Belli ac Pacis libri tres. In quibus ius naturae et Gentium: item iuris publici praecipua explicantur, Amsterdã, I. Blaeu, 1646, Edited by James Brown Scott, Oxford and London, Clarendon Press and Geoffrey Cumberlege, 1925. (The Classics of International Law). Disponível em <http://www.heinonline.org>. Acesso em julho, 2005, prolegomena 1. Sempre que não houver prejuízo para o texto latino, optouse por empregar a tradução para o português em Grotius, Hugo, O Direito da Guerra e da Paz, Trad. Ciro Mioranza, Ijuí, Unijuí, 2004).

33 “(...) sed ni omnes de uberrimo argumento paucissima dixerunt, et ita plerique ut sine ordine quae naturalis sunt iuris, quae divini, quae gentium, quae civilis, quae ex canonibus veniunt, permiscerent atque confunderent" (Ibidem, prolegomena 37).

${ }^{34}$ GROTII, Hugonis, op. cit., nota 19.p. 341 e Grotii, Hugonis, op. cit., nota 28, 25 e 8.
} 
matemáticos consideram as figuras, abstração feita de corpos, de igual modo, tratando do direito, eu afastei o meu pensamento de todo fato particular. ${ }^{35}$

A composição da maturidade consiste num texto essencialmente teórico, sem qualquer objetivo prático e afastado de todos os acontecimentos concretos, tal como os matemáticos abstraem as figuras geométricas dos corpos reais. Os propósitos metodológicos dessa comparação - se eles existirem - revelam-se bem mais singelos do que se poderia pensar: visam apenas justificar a ausência de fatos históricos contemporâneos. Esta comparação com a geometria não implica o emprego nem do método matemático (ou do geométrico), nem mesmo de uma ordem matemática, como aparecia no De Jure Praedae.

O esforço de sistematização, que já constava da monografia de juventude, no De Jure Belli ac Pacis, por sua vez, adquire novos contornos. A estrutura axiomática-dedutiva, que aparecia no capítulo segundo do outro trabalho, não mais subsiste. Em vez disso,

Em toda esta obra me propus sobretudo três coisas: apresentar minhas razões de decidir, apresentando-as tão evidentes quanto possível, dispor em boa ordem as matérias que tinha a tratar, distinguir claramente as coisas que poderiam parecer as mesmas, se comparadas entre si, mas que na realidade não o são. ${ }^{36}$

Grócio, então, observa, ao longo de todo o seu texto, três máximas metodológicas: fundar, tanto quanto possível, as instituições do direito da guerra em evidências, valer-se de uma disposição ordeira das matérias e cuidar de distinguir institutos semelhantes, porém diferentes. Haggenmacher assevera que esta proposta metodológica se refere, em especial, à classificação das fontes do Direito (direito natural e voluntário, direito divino, direito civil, direito das gentes e direito "menor do que civil") que o jurista de Delft expõe no primeiro capítulo. $^{37}$

De acordo com a primeira máxima, Grócio, pois, procura assentar as fontes do Direito em princípios e noções tão fundamentais que as tornem irrefutáveis. No caso do direito natural, isso se apresenta emblemático. $\mathrm{O}$ autor o funda em "noções tão seguras que ninguém as possa negar, a menos que se violente. De fato, os princípios desse direito, se for dada atenção, são claros e evidente de per si [sic], quase tão claros como as coisas que percebemos pelos sentidos externos" ${ }^{\prime 38}$. Aparentemente, a evidência deste jus refere-se ao fato de ele ser racional. Isto está correto, mas incompleto. Para Grócio, "evidência" não representa apenas uma dedução racional e meramente intelectiva, mas também a percepção pelos nossos sentidos. Por isso, o direito natural - que se baseia

\footnotetext{
35 "Iniuriam mihi faciet si quis me ad ullas nostri saeculi controversias, aut natas, aut quae nasciturae praevideri possunt, respexisse arbitratur. Vere enim profiteor, sicut mathematici figuras a corporibus semotas considerant, ita me in iure tractando ab omni singulare facto abduxisse animum." (Grotii, Hugonis, op. cit, nota 28, prolegomena 58).

${ }^{36} \mathrm{Ibidem}$, prolegomena 56. "In toto opere tria maxime mihi proposui, ut definiendi rationes redderem quam maxime evidentes, et ut quae erant tractanda ordine certo disponerem, et ut quae cadem inter se videri poterant necerant, perspicue distinguerem.”

${ }^{37}$ HAGGENMACHER, Peter, op. cit, nota 13.p. 452.

${ }^{38}$ GROTII, Hugonis, op. cit., nota 28, prolegomena 39. “(...) notiones quasdam tam certas ut eas nemo negare possit, nisi sibi vim inferat. Principia enim eius iuris per se patent atque evidentia sunt, multo magis quam quae sensibus externis percibimus (...)
} vol.07, nº. 02, Rio de Janeiro, 2014.pp. 1010-1033 
na razão - é tão evidente como o direito civil, porque este pode ser redigido num codex legal ou ainda ouvido da boca do soberano.

De igual maneira, o direito das gentes revela-se evidente. Para provar a existência deste direito - também como prova auxiliar do direito natural -, Grócio utiliza o testemunho das autoridades (filósofos, historiadores, poetas e oradores). Ele o faz não porque neles confia, sem restrições - já que, segundo o próprio autor, alguns têm o hábito de distorcer a verdade em função dos interesses de sua própria corrente de ideias -, mas porque a concordância de tantos indivíduos, em tempos e lugares diferentes, só poderia provir de uma causa universal. E esta pode ser tanto a decorrência de princípios naturais, como um consenso comum. A primeira alternativa revela o direito natural, e a segunda o jus gentium. ${ }^{39}$

Cumpre ressaltar que esta noção de evidência abrange os dados da empiria, o que significa que Grócio ou discordava dos ataques de Charron ao realismo epistemológico aristotélico, ou não o conhecia. Nas duas hipóteses, resta - vale a pena aqui o emprego da palavra - evidente que o autor não seguia as concepções apriorísticas de Descartes ou Galileu.

O tema da Ordo, por sua vez, em virtude de sua recorrência, representa quase um imperativo para Grócio. No De Jure Praedae, ele se propõe a ser tão ordeiro como os matemáticos e, neste outro livro, no prolegomena 37, ele censurou seus predecessores pela ausência de completude e de ordem. O motivo desta insistência reside no fato de que o autor procurou elaborar um texto completo e sistemático do direito da guerra, com uma adequada classificação das fontes do jus belli logo no início. É esta classificação que permite separar o que de direito da guerra é relativo ao direito natural, ao direito divino e ao direito das gentes. Os autores que o precederam "pouco disseram sobre assunto tão fértil e a maioria o fez mesclando ou confundindo sem ordem alguma o que é relativo ao direito natural, ao direito divino, ao direito das gentes, ao direito civil, que decorrem de cânones $^{\eta 0}$ (grifo nosso). A referência à falta de organização, nos escritores da guerra justa anteriores a Grócio, aparece dentro do mesmo contexto em que ele afirma que eles confundiam as fontes do jus belli. Eis a importância da Ordo para o sistema grotiano: graças a ela, ele consegue escapar à órbita conceitual romana da noção de jus gentium (um direito interno ao Império que se aplicava entre os estrangeiros e se confundia com o direito natural), que persistia em todos os predecessores de Grócio. ${ }^{41}$

\footnotetext{
${ }^{39}$ IBIDEM, prolegomena 40.

${ }^{40}$ IBIDEM, prolegomena 37. “(...) sed ni omnes de uberrimo argumento paucissima dixerunt, et ita plerique ut sine ordine quae naturalis sunt iuris, quae divini, quae gentium, quae civilis, quae ex canonibus veniunt, permiscerent atque confunderent"

${ }^{41} \mathrm{O}$ direito das gentes romano regia as relações dos estrangeiros (peregrini) entre si e com os cives romanos. Era ministrado por um praetor peregrinus, uma figura itinerante; fator que permitiu que seus editos pudessem harmonizar propostas culturais e tradições jurídicas distintas. Consistia, portanto, num direito positivo, mas ele era certamente bastante diferente do jus civile que regia as relações entre os romanos. Ocorre que os romanos não eram bons filósofos e tiveram dificuldades em fundamentar o jus gentium como um direito positivo em vista da divisão binária do Direito que herdaram de Aristóteles (o justo natural e o justo legal). É sintomático o fato de que tanto os grandes juristas compiladores como Gaio e Ulpiano (vide Iustinianus Imperator,
} vol.07, nº. 02, Rio de Janeiro, 2014.pp. 1010-1033 
A terceira máxima metodológica, a distinção entre coisas heterogêneas, refere-se, mais uma vez, à classificação das fontes. Além de Grócio separar o jus gentium do direito natural - em relação aos quais pairava uma persistente indefinição conceitual -, ele diferencia o direito natural do direito voluntário. Esta, inclusive, corresponde à primeira e maior distinção quando o autor introduz as fontes. ${ }^{42}$

Isso é digno de nota. No universo cultural protestante, predominava o voluntarismo e, no mundo católico e ibérico, o intelectualismo tomista. No primeiro, todos os tipos de lei provinham da vontade de um legislador; no caso do direito natural, o legislador era o próprio Deus. No segundo, a lei representava uma medida de retidão, um princípio de organização; desta feita, a inteligência, um desígnio racional e ordeiro, constituía o elemento essencial da lei. Na lei natural, tratava-se do intelecto divino. Por conseguinte, para o ambiente calvinista em que Grócio se inseria, o próprio direito natural era voluntário. Os autores protestantes não podiam caracterizar o direito positivo de voluntário, pois todo o Direito era assim. O jurista holandês, aqui, parece filiar-se à tradição da Escolástica Espanhola. A característica principal do direito positivo, segundo Grócio, reside na sua voluntariedade, não em virtude de se manifestar por escrito (até porque isso excluiria os costumes). O dualismo direito natural e direito voluntário desempenha uma função essencial no desenvolvimento do De Jure Belli ac Pacis. Se um não for separado do outro, a tarefa de produzir uma ciência do Direito deve malograr.

Vários se propuseram até o momento a lhe [o direito da guerra] conferir a forma de uma arte. Ninguém conseguiu. Isso não pode ser conseguido, salvo - sobre isso não há ainda suficiente preocupação - se forem separadas de modo conveniente as coisas que procedem do direito positivo daquelas que decorrem da natureza. Os preceitos do direito natural, sendo sempre os mesmos, podem facilmente ser reunidos em regras de arte, mas as disposições que procedem do direito positivo, mudando muitas vezes e variando de acordo com os lugares, estão acima de todo sistema metódico, como as outras noções das coisas privadas [sic; substitua-se esta palavra por "singulares"].43

Grócio se propôs a redigir um texto de teoria e, para tanto, faz-se necessário observar nos fenômenos certa regularidade e constância. Contudo, apenas o direito natural mostra-se invariável e universal: o direito

Corpus Iuris Civilis, ed. Krueger e Mommsen, Berlim, Weidmann, 1908, Digesto, 1, 1, 1, 4 e 1, 1, 9), quanto um filósofo como Cícero (vide Cícero, Marco Túlio, Dos Deveres, Trad. Angélica Chiapeta, São Paulo, Martins Fontes, 1999. p. 136 e 157) ou conferem um fundamento natural ao direito das gentes ou tratam-no como sinônimo do direito natural. Essa confusão permanece durante todo o medievo e persiste até mesmo num pensador como Francisco de Vitória. Para maiores esclarecimentos, vide Borges de Macedo, Paulo Emílio, O mito de Francisco de Vitória: defensor dos direitos dos índios ou patriota espanhol? Boletim da Sociedade Brasileira de Direito Internacional, n. 119-124, v. 1, pp. 90-110, ano XCVIII, agosto/dezembro 2013.

${ }^{42}$ GROTII, Hugonis, op. cit, nota 28, I, 1,9.

43 "Artis formam ei imponere multi ante hac destinarunt: perfecit nemo: neque vero fieri potest nisi, quod non fatis curatum est hactenus, ea quae ex constituto veniunt a naturalibus recte separentur. nam naturalia cum semper eadem sint facille possunt in artem colligi: illa autem quae ex constituto veniunt, cum et mutentur saepe et alibi alia sint, extra artem posita sunt, ut aliae rerum singularium perceptiones." (IBIDEM, prolegomena 30). 
positivo revela-se inconstante e funda-se em opinião, na doxa. Os antecessores de Grócio não conseguiram escrever um corpo teórico, porque misturavam elementos positivos com naturais.

As três máximas metodológicas, portanto, não guardam relações nem com o método geométrico, nem com o matemático, mas com a completude e sistematização observadas na composição do De Jure Belli ac Pacis. Constituem preocupações metodológicas - não há dúvidas -, mas não como as de um Descartes ou de um Galileu. Correspondem mais aos esforços de sistematização do estudo do Direito empreendido pelos juristas franceses, adequados aos preceitos do mos gallicus. A atenção que estes juristas despediam ao método encontrava-se conforme o espírito da época, mas nunca atingiram os níveis ou a sofisticação da escola paduana.

Por fim, aquilo que Grócio considerava método no De Jure Praedae, ressurge como "meio de prova" vinte anos mais tarde. Comprova-se o direito natural a priori pela conveniência da coisa com a natureza racional e social, e a posteriori pela concordância de todas as nações (ou entre as mais civilizadas). ${ }^{44}$ A opinião dos textos antigos, da Bíblia e dos bons escritores fornecem "evidência histórica". Também na obra de maturidade, o autor valoriza mais a primeira forma e reserva à segunda uma função meramente confirmatória. No entanto, não se deve depreender disso a sua inferioridade, uma vez que, como supracitado, é dessa maneira que se "evidencia” o direito das gentes.

O juízo, portanto, que Grócio profere, no prolegomena 38, dos seus antecessores, acerca da falta da "luz da história", equivale a uma reprovação de grau metodológico. Faltavam-lhes evidências suficientes para embasar os seus argumentos. Para suprir essa ausência, eles compensavam por elevar as ideias de Aristóteles ao grau de verdade absoluta, o que, Grócio reputava nocivo, apesar de seu próprio estilo ser um tanto ornamental. O autor vale-se dos autores antigos não como um recurso à autoridade somente, mas para prover-se de certeza histórica. Cumpre salientar que o uso da História por Grócio em nada lembra o esforço de investigação de um historiador contemporâneo; significa, antes, a referência a eventos da Antiguidade, quanto mais antigos, maior a força dos exemplos. E trata-se de uma referência indireta, sempre mediada pela Bíblia ou pelos escritores clássicos. Ainda assim, o emprego da História representa, para o jurista de Delft, um cuidado metodológico.

A preocupação metodológica que Grócio presenciou, em sua época, era generalizada e representava uma reação à tradição medieval. Algumas vertentes incorporaram-se à modernidade, enquanto outras se perderam no tempo. Mas, de um modo geral, o método não ocupa, no pensamento de Hugo Grócio, a mesma posição de destaque daquela do sistema cartesiano. Consoante Haggenmacher, a epistemologia do autor ainda parece um tanto "ingênua", típica de um universo cultural pré-moderno. ${ }^{45}$ Contudo, neste aspecto, faz-se mister produzir um acordo semântico sobre o que constitui ou não um método moderno. Se forem considerados apenas os de

\footnotetext{
${ }^{44}$ IBIDEM, I, 1, 12.

${ }^{45}$ HAGGENMACHER, Peter, op. cit., nota 15, p. 69.
} 
Descartes e de Galileu, então, de fato, Grócio não passa de um legítimo representante do mos gallicus no direito da guerra. Mas essa interpretação exclui da modernidade até mesmo os empiristas ingleses.

\title{
CONCLUSÃO
}

Hugo Grócio encontra-se sempre no limiar entre a modernidade e o medievalismo. A atenção que este autor dispensa ao método assemelha-se muito àquela dos escritores tipicamente modernos: a referência à matemática como modelo de investigação, a estrutura axiomática da monografia de juventude e sistemática no trabalho da maturidade e a centralidade dessa questão nas suas duas obras principais. Apesar disso, o leitor se depara com um estilo bastante ornamental e repleto de remissões à autoridade dos textos antigos, características típicas dos textos medievais. Grócio causa estranheza.

Em verdade, o pensamento do jurista holandês apresenta mais uma aparência de modernidade do que uma preocupação metodológica de fundo. O recurso à matemática, numa obra, serve para a ordenação da narrativa, noutra, como fonte de inspiração para um texto de teoria pura. Grócio pretendia apenas concatenar as suas ideias da maneira mais clara possível e embasar os seus argumentos em dados históricos e racionais.

Ainda assim, revela-se digno de nota o método constituir, de fato, um problema num pensador anterior a Descartes. Grócio se ocupou do método como nenhum outro doutrinador da guerra justa havia feito. As formas medievais de persuasão e convencimento não mais satisfaziam. Em Grócio, o recurso às autoridades clássicas consistia menos numa falácia do que numa fonte de verdades históricas. As Escrituras só encerram evidências quando revelam acontecimentos do passado.

O humanismo jurídico revela-se um período bastante fértil e impregnado de concepções um tanto incomuns, as quais não podem ser consideradas modernas, mas que guardam importantes diferenças em relação ao medievo. Se Grócio não é um autor moderno, então, quiçá, a modernidade tenha sido mais uma evolução gradual do uma verdadeira revolução.

\section{MODERNITY AND MEDIEVALISM IN GROTIUS: THE DISCOURSE OF THE METHOD}

\begin{abstract}
:
One of the most distinctive notes in Modern thinkers is their concern with the method of investigation. In order to break with the past and, at the same time, build a solid system of thought, Modern authors turned their attention to the "hard" sciences and introduced their method in the study of Politics and Law. The authority of ancient texts, by itself, would no longer have anything to teach. Much has been discussed about the membership of Hugo Grotius amongst Modernity, but if, on the one hand, the presence of a mathematical method in its thought
\end{abstract}


is one of the main modern features, then this author integrates the ranks of Modernity. On the other hand, the use of such a mathematical method in Grotius is so full of nuances that induces the reader to question the seriousness of his choice. Regarding method, the Dutch jurist is "more or less" modern, or "more or less" medieval, depending on the optics. Or perhaps the Modern Revolution was not so revolutionary and Hugo Grotius was a transitional author.

Keywords: Hugo Grotius, Modernity, method.

\section{BIBLIOGRAFIA}

BOBBIO, Norberto, Thomas Hobbes, Trad. Carlos Nelson Coutinho, Rio de Janeiro, Campus, 1991.

BORGES de MACEDO, Paulo Emílio, O mito de Francisco de Vitória: defensor dos direitos dos índios ou patriota espanhol? Boletim da Sociedade Brasileira de Direito Internacional, n. 119-124, v. 1, pp. 90-110, ano XCVIII, agosto/dezembro 2013.

BULL, Hedley; KINGSBURY, Benedict; ROBERTS, Adam (ed.), Hugo Grotius and International Relations, Oxford and New York, Oxford University and Clarendon Press, 2002.

CEDRONI, Lorella, La Comunitá Perfetta: il pensero politico di Francisco Suárez, Roma, Studium, 1996.

CÍCERO, Marco Túlio, Dos Deveres, Trad. Angélica Chiapeta, São Paulo, Martins Fontes, 1999.

DUFOUR, Alfred, L'influence de la méthodologie des sciences physiques et mathématiques sur les Fondateurs del'École du Droit naturel moderne (Grotius, Hobbes, Pufendorf), Grotiana, v. I, pp. 33-52, 1980.

EIKEMA HOMMES, Hendrik van, Grotius on Natural and International Law, Netherlands International Law Review, v.XXX, pp. 61-71, 1983.

GROTII, Hugonis, De Iure Belli ac Pacis libri tres. In quibus ius naturae et Gentium: item iuris publici praecipua explicantur, Amsterdã, I. Blaeu, 1646, Edited by James Brown Scott, Oxford and London, Clarendon Press and Geoffrey Cumberlege, 1925. (The Classics of International Law). Disponível em <http://www.heinonline.org>. Acesso em julho, 2005.

De Jure Praedae Commentarius, La Haye, Hamaker, Nijhoff, 1868.

Epistolae Quotquot reperiri potuerunt; In quibus praeter hactenus Editas, plurimae Theologici, Iuridici, Philologici, Historici \& Politici argumenti occurrun, Amstelodami, P. \& I. Blaev, 1687, Carta a D. Galilaeo Galilaei, n. 654 .

GROTIUS, Hugo, O Direito da Guerra e da Paz, Trad. Ciro Mioranza, Ijuí, Unijuí, 2004.

GROTIUS, Hugues, Le droit de la guerre et de la paix de Hugues Grotius, Trad. J. Barbeyrac, Amsterdam, Pierre de Coup, 1724.

HAGGENMACHER, Peter, Grotius et la doctrine de la guerre juste, Genève, Paris, Heige, Presses Universitaires de France, 1983. 
HINOJOSA, Eduardo, Influencia que tuvieron en el Derecho Público de su pátria y singularmente en el Derecho penallos filósofos y teólogos españoles, anteriores a nuestro siglo, Madrid, Reus, 1890.

HOLLAND, Thomas E., Alberico Gentili: an inaugural lecture delivered at All Souls College, November 7, 1874, en Studies in International Law, Oxford, Clarendom Press, 1898.

IUSTINIANUS IMPERATOR, Corpus Iuris Civilis, ed. Krueger e Mommsen, Berlim, Weidmann, 1908.

MERÊA, Paulo, Suárez, jurista. O problema da origem do poder civil, Estudos de Filosofia Jurídica e de História das Doutrinas Políticas, Lisboa, Imprensa Nacional-Casa da Moeda, 2004.

NYS, Ernest, Le Droit de la Guerre et les précurseurs de Grotius, Bruxelles et Leipzig, Murquardt, 1882.

PUFENDORF, Samuel, Of the Law of Nature and Nations, Trad. B. Kenneth, London, 1729.

REALE, Miguel, Horizontes do Direito e da História, 3. ed., São Paulo, Saraiva, 2000.

RIVIER, Alphonse, Note sur la littérature du droit de gens avant la publication du Jus Belli ac Pacis de Grotius (1625), Bruxelles, Académie Royale de Belgique, 1883.

SCIACCA, Michele, Perspectiva dela metafisica en Sto. Tomas, Madrid, Speiro, 1976.

SCOTT, J. B., The Catholic Conception of International Law, Washington D.C., Georgetown University Press, 1934.

TRUYOL y SERRA, Antonio et al. Actualité de la Pensée Juridique de Francisco de Vitoria, Bruxelles, Bruylant, Centre Charles De Visscher pour le droit international, 1988.

TUCK, Richard, Grotius, Carneades e Hobbes, Grotiana, v. 4, pp. 43-63, 1983.

Natural Rights Theories: their origin and development, New York, Cambridge University Press, 1979.

VERMEULEN, Ben, Simon Stevin and the Geometrical Method in De jure praedae, Grotiana, v. 4, pp. 63-67, 1983.

VOLLENHOVEN, Cornelius van, Grotius and the Study of Law, The American Journal of International Law, v. 19, n. 1, pp. 1-11, janeiro de 1925.

WIJFFELS, Alain, Early-Modern Literature on International Law and the Usus Modernus, Grotiana, v. 16-17, pp. 35-54, 1995-1996.

Trabalho enviado em 11 de maio de 2014.

Aceito em 23 de agosto de 2014. 